\title{
The Application of Microfadeometric Testing to Mounted Photographs at the Indianapolis Museum of Art
}

Michael R. Columbia ${ }^{1}$, Gregory D. Smith ${ }^{2}$, Claire Hoevel ${ }^{3}$ and Paul Messier ${ }^{4}$

1. Chemistry Department, Indiana University Purdue University Fort Wayne, Fort Wayne, IN USA

2. Conservation Science Laboratory, Indianapolis Museum of Art, Indianapolis, IN USA

3. Conservation Department, Indianapolis Museum of Art, Indianapolis, IN USA

4. Paul Messier LLC, Boston, MA USA

The effect of light on the colorants used in art has been a subject of scientific investigation for over 200 years; a major impetus for these endeavors is the control of lighting conditions in museums, so that damage to art objects is minimized [1]. In first half of the $20^{\text {th }}$ century, developing accelerated methods for testing the rate at which colorants fade has been the focus of considerable effort within the textile industry. Organizations, such as the Society of Dyers and Colorists (SDC) in the UK and the American Association of Textile Chemists and Colorists (AATCC) in the US, have established and updated standardized methods for performing fadeometry. These methods rely on comparison of the fading of a colorant, as measured by the overall change in reflected light $(\Delta \mathrm{E})$, to that of eight standard blue dyes on wool fabric [2].

Whitmore, et al. reported the first application of fadeometry on a microscale [3]. The apparatus developed for this utilizes two fiber optics: one to focus visible light from an intense xenon lamp as a $200-400 \mu \mathrm{m}$ spot, while the second collects a portion of the reflected light for analysis using a diodearray spectrometer. Thus the fading behavior of an artwork can be probed without causing changes to its appearance that might be detected by the naked eye. The information acquired from this technique can help determine the lighting conditions and duration of exhibition best suited to balance the display and longevity of the artwork [4].

As part of a grant from the Institute for Museum and Library Sciences (IMLS), microfadeometry has been used to determine the fading behavior of color photographs in the collection of the IMA. A large challenge in this endeavor has been characterizing those photographs, either face-mounted to the glazing, or mounted with a gap between the photograph and the glazing. Fadeometry studies of such photographs have not been reported in the literature.

In both mounting arrangements, reflective losses from the glazing surface potentially minimize the light intensity reaching the photograph. To address this, the fading measurements for the blue wool standards have been made through glazing similar to that used in the photograph. Figure 1 depicts the measurement of such a photograph and Figure 2 shows the successful comparison of the fading of various locations within the photograph to that of Blue Wools \#1, \#2 and \#3 measured through similar glazing. When a gap is also present, alignment of the fiber optics becomes an issue, as well. Modifications to the fiber optic holder have been made to allow recovery of this alignment, while still focusing the spot of light to an acceptably small size. 


\section{References}

[1]. J. Druzik and B. Eshoj, in "Museum Microclimates" (The National Museum of Denmark), p. 51

[2] M. Clark in "Dyeing For a Living" (AATCC, Research Triangle Park), p. 248.

[3] P. M. Whitmore, et al., Journal of the American Institute for Conservation, 38 (1999), p. 395.

[4] A. G. Pignani, et al., IEEE Sensors Journal, 3 (2003), p. 108
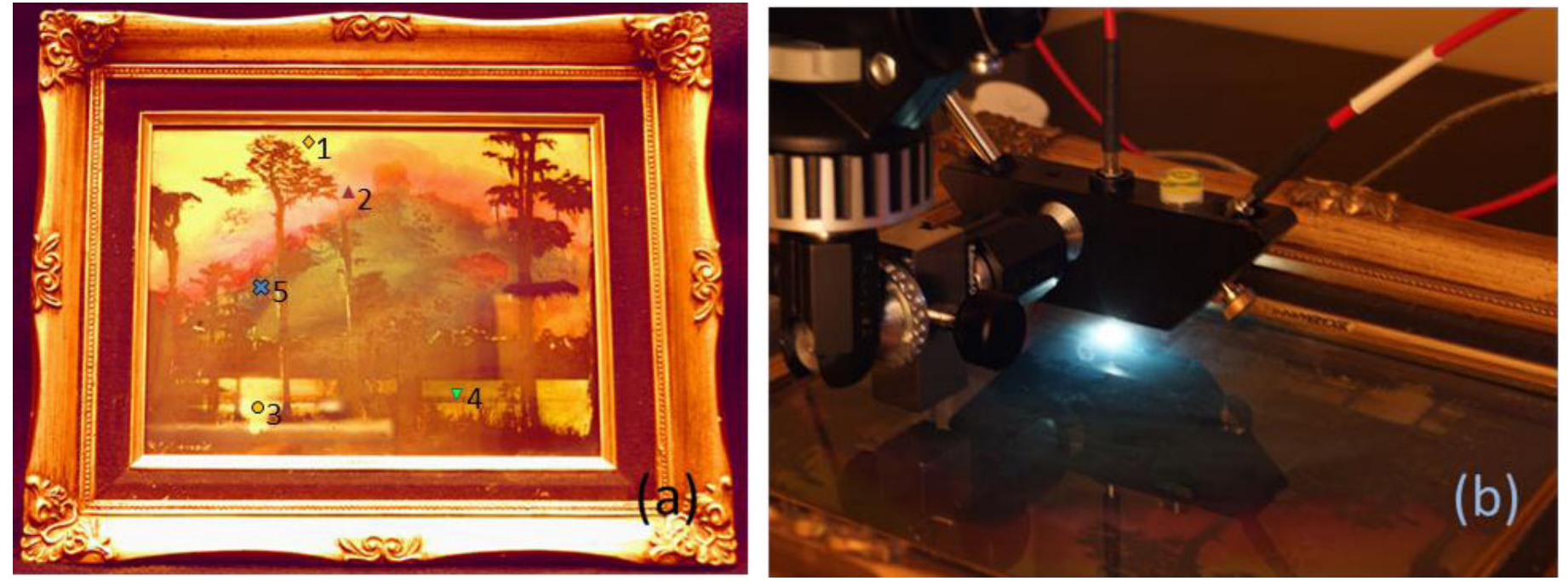

Figure 1. (a) Orotone photograph attributed to E. G. Barnhill, (b) Microfadeometric analysis in progress

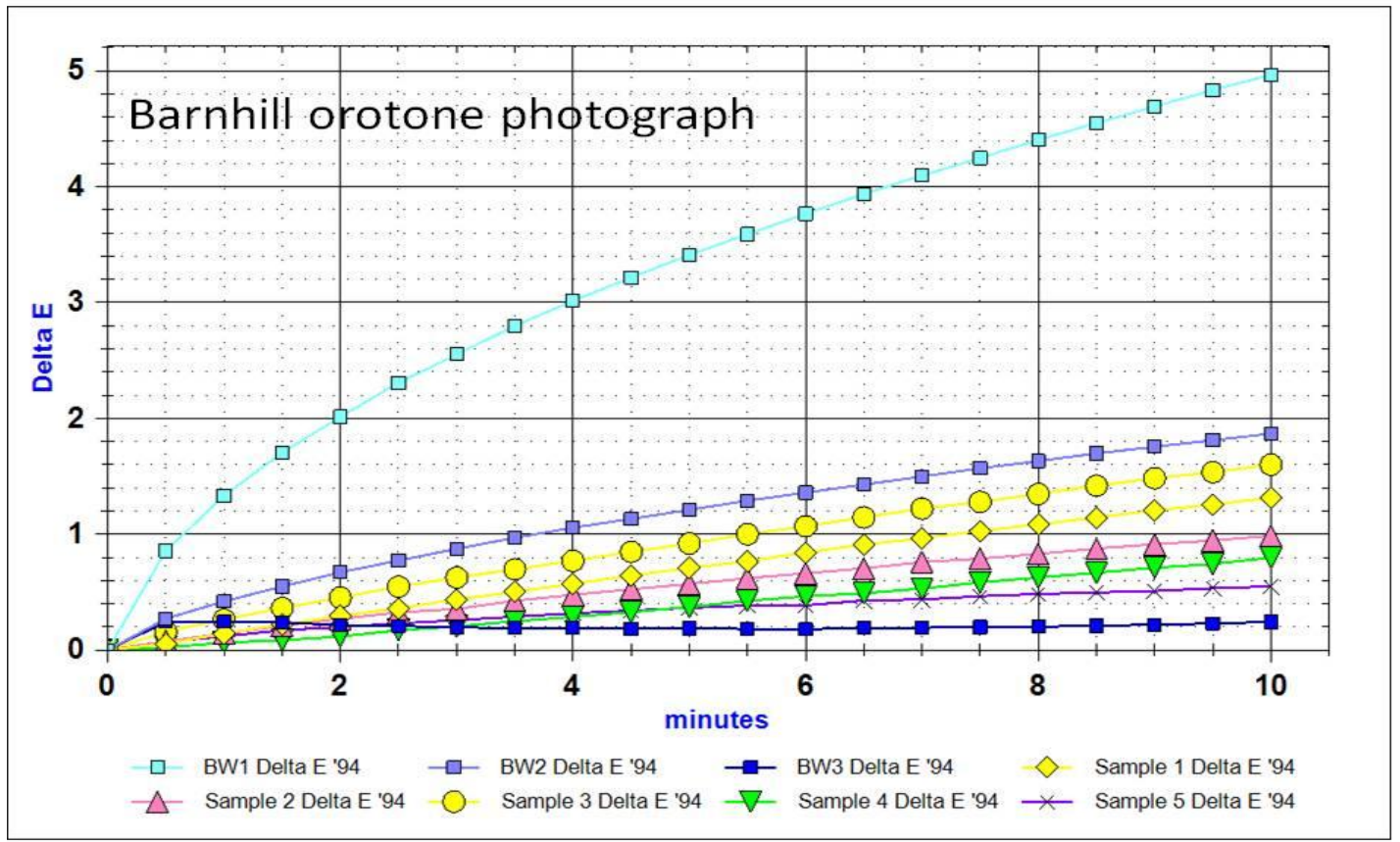

Figure 2. Fading curves (Delta $E$ vs. time) for Blue Wools \#1, \#2 and \#3 (measured under $3 \mathrm{~mm}$ thick acrylic glazing), and five sample locations indicated on the orotone photograph. 